\title{
Preparation and gas barrier characteristics of polysilazane derived multi-layered silica thin films formed on alicyclic polyimide film using ultraviolet irradiation
}

\author{
Tomoji Ohishi* and Kazuya Yanagida \\ Department of Applied Chemistry, Faculty of Engineering, Shibaura Institute of Technology, Toyosu, Koto-ku, Tokyo, Japan
}

\begin{abstract}
With the aim of developing high-performance gas barrier films, the multi-layer coating method that uses ultraviolet irradiation to a polysilazane coating formed on an alicyclic polyimide film has been investigated. The multi-layered gas barrier film consisting of five layers was prepared by using organic polysilazane to form an intermediate stress relaxation layer. This multi-layered film is smooth and uniform, with no cracks, exhibiting superior gas barrier properties. The film is also transparent and highly heat resistant (alicyclic polyimide, $\mathrm{Tg}: 300^{\circ} \mathrm{C}$ ), making it useful for the formation of flexible devices.
\end{abstract}

\section{Introduction}

In recent years, significant process has been made in the development of electronic terminal devices such as mobile phones and televisions, and electronics-related products such as solar cells, and there are calls for the development of products with greater functionality and performance [1-4]. In particular, for the next generation of electronic devices, attention is turning to products with flexible properties such as wearable devices, flexible batteries, electronic paper and flexible display devices that are thin, light and flexible $[5,6]$. A flexible substrate is an essential constituent of such products. Flexible substrates are generally made using flexible organic resin films. However, ordinary organic films do not perform well at blocking the passage of gases such as oxygen, water vapor and the like. This can result in problems such as oxidation of device elements formed on these films, leading to serious performance degradation issues. There is consequently a strong demand for the development of flexible substrates with better gas barrier characteristics. One way of improving the gas barrier characteristics of an organic film is to add a dense inorganic coating, but the low heat resistance of the organic film makes it difficult to form an inorganic gas barrier coating with adequate performance. The most popular approach involves using large-scale high-vacuum film deposition apparatus to form multiple layers of $\mathrm{SiO}_{2}$-based coatings or inorganic oxide coatings by using methods such as sputtering or vacuum deposition to restrict the temperature to which the substrate is heated [7-12]. However, this approach is not only costly due to the use of complex vacuum equipment, but also results in gas barrier characteristics that are still inadequate. Another simpler approach involves coating the organic film with an inorganic precursor solution [13-17], but since it has to be heated to several hundred degrees Celsius in order to form a dense inorganic coating, this approach cannot easily be applied to organic films with low heat resistance.

Recently, organic films with better gas barrier characteristics have been developed by studying methods that use irradiation and polysilazane coatings with excimer light or ultraviolet light to form dense inorganic coatings on PET films at lower temperatures [18-
24]. We have successfully developed a highly transparent and highly heat-resistant alicyclic polyimide film and a PET film with good gas barrier characteristics by using ultraviolet rays from a low-pressure mercury lamp to irradiate a polysilazane coating while applying heat [25-26]. In this article, we report on how this method can be used to form multi-layer gas barrier coatings on alicyclic polyimide films with even better performance, and we present the results of examining their characteristics. To explore the causes of this gas barrier performance, we also discuss the results of examining the film's surface state by AFM, and the film's electrical properties such as its dielectric breakdown properties.

\section{Experimental}

\section{Preparation of silica coatings by using light irradiation}

As a precursor for forming thin coatings, a solution of polysilazane (perhydropolysilazane: PHPS) in dibutyl ether (NL-110, $20 \mathrm{wt} \%$ : AZ Electronic Materials Co.) was used. This polysilazane solution was diluted to $5 \mathrm{wt} \%$ in dibutyl ether and spin-coated onto an alicyclic polyimide film (PI, thickness $100 \mu \mathrm{m}$, Mitsubishi Gas Chemical Co.) that had been processed to make it hydrophilic. A low-pressure mercury lamp was used to irradiate the film with light while exposed to the air. The film was irradiated at $12 \mathrm{~mW} / \mathrm{cm}^{2}$ for 20 minutes. This irradiation on substrates held at four different temperatures: $80^{\circ} \mathrm{C}, 100^{\circ} \mathrm{C}, 120^{\circ} \mathrm{C}$ and $150^{\circ} \mathrm{C}$ was performed. Coatings were applied to both sides of the film. Samples by similar methods at two different spin coating rotation

Correspondence to: Tomoji Ohishi, Department of Applied Chemistry, Faculty of Engineering, Shibaura Institute of Technology, 3-7-5 Toyosu, Koto-ku, Tokyo 135-8548, Japan, Tel:+81-5859-8154, FAX: +81-5859-8100; E-mail: tooishi@sic.shibaura-it.ac.jp

Key words: polysilazane, photo-irradiation, gas barrier characteristics, alicyclic polyimide film, flexible electronics

Received: September 15, 2016; Accepted: September 26, 2016; Published: September 28, 2016 

irradiation

speeds: $800 \mathrm{rpm}$ and $600 \mathrm{rpm}$ were prepared. Comparative samples that were only subjected to heat treatment $\left(\right.$ at $150^{\circ} \mathrm{C}, 200^{\circ} \mathrm{C}, 250^{\circ} \mathrm{C}$ and $300^{\circ} \mathrm{C}$ for 20 minutes) were also prepared.

\section{Preparation of multi-layer coatings}

Preparation of methylperhydropolysilazane (MHPS): $100 \mathrm{wt} \%$ methylperhydropolysilazane (Toresumairu HTA 1500, Sanwa Kagaku Co.) was diluted with dibutyl ether to form a $5 \mathrm{wt} \%$ solution of MHPS.

Preparation of the multi-layer coating: Using a $5 \mathrm{wt} \%$ solution of PHPS, two layers of PHPS-derived $\mathrm{SiO}_{2}$ on a PI film according to the previously mentioned method shown in section 2.1 were formed. Light irradiation was performed at an intensity of $12 \mathrm{~mW} / \mathrm{cm}^{2}$ for 20 minutes at a substrate temperature of $150^{\circ} \mathrm{C}$. This was then covered with a $5 \%$ solution of MHPS by spin coating (1000 rpm, 60 seconds), followed by heat treatment at $120^{\circ} \mathrm{C}$ for 20 minutes to form the intermediate layer (MHPS-derived $\mathrm{SiO}_{2}$ ) of the multi-layer coating. On top of that, two layers of PHPS-derived $\mathrm{SiO} 2$ were formed according to the method using a $5 \mathrm{wt} \%$ solution of PHPS.

\section{Evaluation}

The surface of the coating with an atomic force microscope (AFM:5100N, Hitachi Hightech Science Co.) was observed. The cross-sectional structure of the coating with a transmission electron microscope (TEM:H-9000NAR, Hitachi Ltd.) was also observed. The TEM observation samples were prepared by FIB (Focused Ion Beam) processing. By using X-ray photoelectron spectroscopy (XPS: Quantera II, PHI Co.) an elemental analysis while sputtering from the upper surface of the coating layers was performed. To assess the gas barrier characteristics, the water vapor permeability $\left(40^{\circ} \mathrm{C}, 90 \% \mathrm{RH}\right.$ : Mocon Permatran-W or Aquatran) was measured. Water vapor transmission rates of $1 \mathrm{~g} / \mathrm{m}^{2} \cdot$ day or above were measured using the dish method. The water vapor permeability of the multilayer coating was measured at a humidity of $90 \% \mathrm{RH}$ and at temperatures of $40^{\circ} \mathrm{C}, 50^{\circ} \mathrm{C}$ and $55^{\circ} \mathrm{C}$. The adhesion strength and hardness of the coating on the PI film were evaluated by performing tape peeling and pencil hardness tests according to JIS standards (JIS K5600). The dielectric breakdown field strength was obtained from the voltage-current characteristics of a single-layer coating formed on a silicon substrate. An electrode $(\mathrm{Au}(100 \mathrm{~nm}) / \mathrm{Ti}(10 \mathrm{~nm}))$ on the coating was formed and measured the current flowing through it while varying the voltage between 0 and $20 \mathrm{~V}$. The dielectric breakdown field strength was estimated from the voltage at which there was a sudden increase in current, based on the formula voltage $(\mathrm{V}) /$ film thickness $(\mathrm{cm})$.

\section{Results and discussion}

\section{Preparation and properties of $\mathrm{SiO}_{2}$ films derived from polysilazane}

The coatings formed on polyimide films have very smooth surfaces, and when observed at magnifications of 10,000 to 20,000 with a scanning electron microscope (SEM), it was not possible to observe any differences between coatings formed under different conditions. Therefore AFM measurements were performed, which enable the observation of finer structures.

Figure 1 shows AFM images of (a) the PI surface, (b) the polysilazane (PHPS) coating (before light exposure), and (c) singlelayer and (d) two-layer coatings after light exposure at $150^{\circ} \mathrm{C}$. In the unexposed coating, it can be seen that the surface state is similar to that of the PI surface. In the exposed single coating surface, it is possible to see small particles of approximately $2-3 \mathrm{~nm}$ in size. These are thought to have formed due to the growth of fine $\mathrm{SiO}_{2}$ particles. In the two-layer coating, it can be seen that the surface is even smoother. This is thought to be because the surface irregularities in the single coating surface are smoothed out by being buried under the PHPS solution during the second spin-coating stage.

Figure 2 shows the surface state of coatings after light irradiation and heat treatment (two-layer coatings) while varying the temperature at which the coatings are formed. In the coatings irradiated with light, it can be seen that the occurrence of particles and irregularities decreased with increasing temperature (room temperature $\rightarrow 100^{\circ} \mathrm{C} \rightarrow 150^{\circ} \mathrm{C}$ ), resulting in a smoother surface. On the other hand, in the heat-treated coatings, the growth of surface particles increased with increasing heat-treatment temperature $\left(150^{\circ} \mathrm{C} \rightarrow 250^{\circ} \mathrm{C} \rightarrow 300^{\circ} \mathrm{C}\right)$ was observed. Light irradiation thus resulted in coating surfaces that were smoother and more compact. The difference in surface states between the lightirradiated coatings and heat-treated coatings suggests that there are different generation and growth mechanisms at play in the transition from PHPS to an $\mathrm{SiO}_{2}$ coating, although the details of these mechanisms are currently not clear.

Figure 3 compares the surface hardness (pencil hardness test) values of the light-exposed and heat-treated coatings. Since a dense $\mathrm{SiO}_{2}$

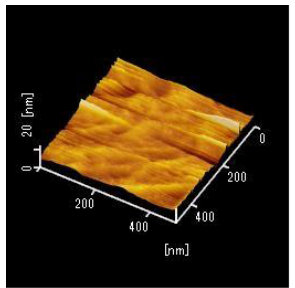

(a) Polyimide

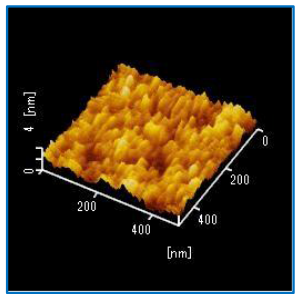

(c) 1-coat film $\left(\mathrm{UV}+150^{\circ} \mathrm{C}\right)$

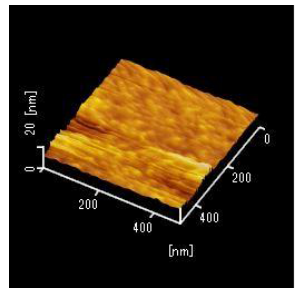

(b) Polysilazane film( No UV)

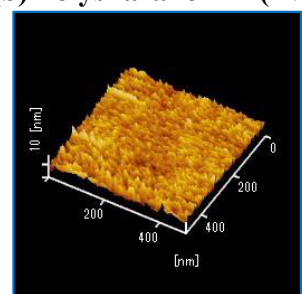

(d) 2-coat film $\left(\mathrm{UV}+150^{\circ} \mathrm{C}\right)$
Figure 1. Surface AFM images of polysilazane-derived $\mathrm{SiO}_{2}$ films.

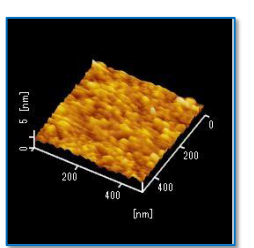

r.t. +UV
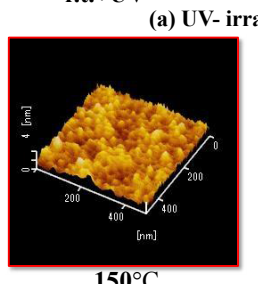

$150^{\circ} \mathrm{C}$

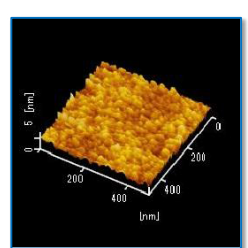

$100^{\circ} \mathrm{C}+\mathrm{UV}$ arious temperature

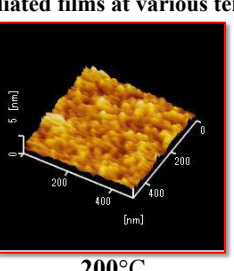

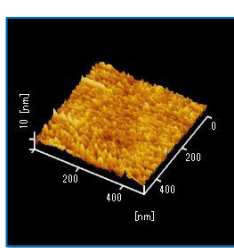

$150^{\circ} \mathrm{C}+\mathbf{U V}$

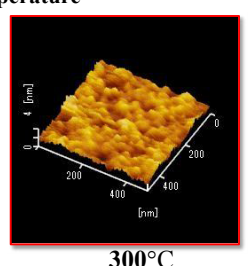

$300^{\circ} \mathrm{C}$ (a) Heat-treated films at various temperature

Figure 2. Comparison of surface AFM images of UV-irradiated and heat-treated films. 


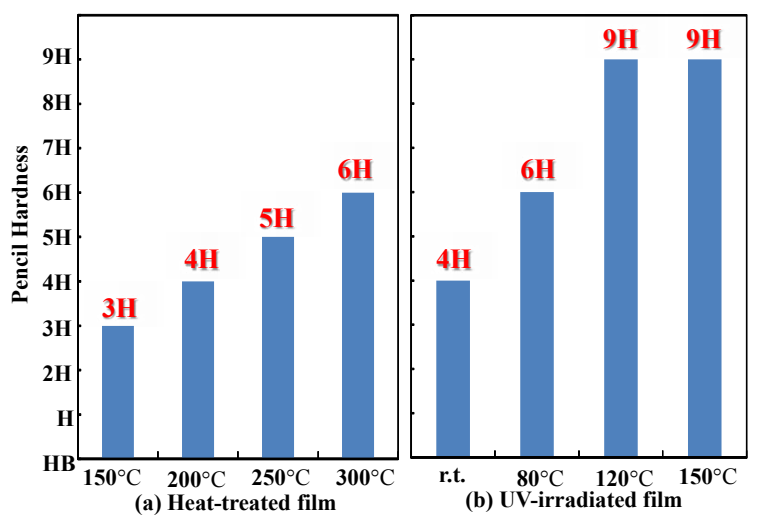

Figure 3. Surface hardness of heat-treated and UV-irradiated films.

coating has greater surface hardness, it can be used as one indicator of how dense the coating is. As the polysilazane coating heat treatment temperature was increased from $150^{\circ} \mathrm{C}$ to $300^{\circ} \mathrm{C}$, the surface hardness increased from $3 \mathrm{H}$ to $6 \mathrm{H}$. On the other hand, the surface hardness of the light irradiated film also increased with as the temperature at the time of light irradiation increased - from $4 \mathrm{H}$ at room temperature to $9 \mathrm{H}$ at $120^{\circ} \mathrm{C}$ or above. The increased surface hardness is due to resulting from increased conversion of the polysilazane coating to silica $\left(\mathrm{SiO}_{2}\right)$, and increasing compactness of this coating. It is thought that the increased silica $\left(\mathrm{SiO}_{2}\right)$ conversion and the increased compactness of this coating with light irradiation occurred at temperatures substantially lower than those used for heat treatment. Changes in the coating's chemical structure during light irradiation can be tracked by examining the infrared absorption spectrum. It has already been reported that the transition from polysilazane coating to silica takes place at temperatures much lower than those required for heat treatment $[25,26]$. In the oxidation reaction of the polysilazane coating, it is inferred that contributions are made by the oxidation effects of $\mathrm{O}_{3}$ and $\mathrm{O}\left({ }^{1} \mathrm{D}\right)$ active oxygen derived from atmospheric oxygen, and by the chemical bond cleavage effects of optical energy supplied by the low-pressure mercury lamp at wavelengths of $254 \mathrm{~nm}$ and $185 \mathrm{~nm}$. The energy levels of light with wavelengths of $254 \mathrm{~nm}$ and $185 \mathrm{~nm}$ are 113 and $155 \mathrm{kcal} / \mathrm{mol}$, respectively. The $\mathrm{Si}-\mathrm{N}$ and $\mathrm{N}-\mathrm{H}$ bond energies of polysilazane are 105 and $92 \mathrm{kcal} / \mathrm{mol}$, respectively, while the lowpressure mercury lamp produces light with more energy than these bonds, allowing it to break these bonds efficiently. An Si atom whose bonds have broken immediately reacts with the activated oxygen to form $\mathrm{SiO}_{2}$. The substrate temperature increases the rate of activated oxygen diffusion and promotes oxidation reactions in the vicinity of polysilazane bonds that have been broken by the optical energy, which contributes to the formation of inorganic $\mathrm{SiO}_{2}$.

Figure 4 shows the current-voltage characteristics of the polysilazane film. From the voltage at which the current increases sharply, the dielectric breakdown field strength of the oxide coating can be estimated, which is one indicator of the insulating film's compactness. This polysilazane film substrate was compared with single-coating films formed on a $\mathrm{Si}$ substrate. The figure also shows the results for two coating layers formed by light irradiation at $150^{\circ} \mathrm{C}$. For the light irradiated films at temperatures ranging from room temperature up to $120^{\circ} \mathrm{C}$, the current increased suddenly at around $10-11 \mathrm{~V}$ (the region above $10 \mathrm{~V}$ is not shown for this reason). For the light irradiated at $150^{\circ} \mathrm{C}$, the sudden current jump occurred at $15.6 \mathrm{~V}$. Based on this value, the dielectric breakdown strength of the coating is $1.2 \mathrm{MV} / \mathrm{cm}$. Meanwhile, the two-layer coating irradiated with light at $150^{\circ} \mathrm{C}$ underwent no large change in DC current even when subjected to $20 \mathrm{~V}$, showing that it had a large dielectric breakdown field strength. This demonstrates that the use of multiple layers makes the coating denser. On the other hand, the DC current increased rapidly at $5.5 \mathrm{~V}$ in the coating subjected to heat treatment at $150^{\circ} \mathrm{C}$. Coatings subjected to light irradiation are denser than coatings subjected to thermal processing. The compactness of a coating is thought to have a major effect on the improvement of gas barrier characteristics.

Figure 5 shows the gas barrier characteristics of the polysilazane films. The water vapor transmission rate of the heat-treated coating decreased from $143 \mathrm{~g} / \mathrm{m}^{2}$ * day for the ordinary PI film, to $48.6 \mathrm{~g} / \mathrm{m}^{2}$ - day for coatings heat treated to $150^{\circ} \mathrm{C}, 36.9 \mathrm{~g} / \mathrm{m}^{2}$ - day for $200^{\circ} \mathrm{C}$, $2.26 \mathrm{~g} / \mathrm{m}^{2}$ - day for $250^{\circ} \mathrm{C}$, and $1.14 \mathrm{~g} / \mathrm{m}^{2}$ - day for $300^{\circ} \mathrm{C}$. On the other hand, for the coatings subjected to light irradiation, we obtained better gas barrier characteristics than with heat-treated coatings when heating to $80^{\circ} \mathrm{C}\left(1.77 \mathrm{~g} / \mathrm{m}^{2}\right.$ - day $) \rightarrow 100^{\circ} \mathrm{C}\left(1.22 \mathrm{~g} / \mathrm{m}^{2}\right.$ - day $) \rightarrow 150^{\circ} \mathrm{C}$ $\left(0.08 \mathrm{~g} / \mathrm{m}^{2} \cdot\right.$ day $)$. This demonstrates that our method is effective for the formation of gas barrier coatings at low temperatures.

Figure 6 shows the gas barrier characteristics of samples obtained while varying the spin coating rotation speed used to form the polysilazane coatings. As the rotation speed decreases from $1000 \mathrm{rpm}$ to $800 \mathrm{rpm}$ and $600 \mathrm{rpm}$, the transmission rate decreases from 0.08

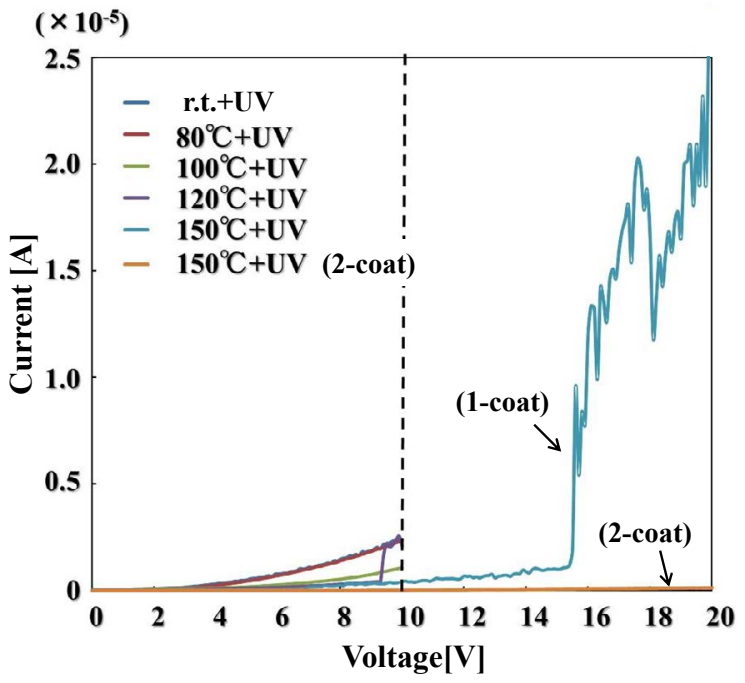

Figure 4. Breakdown field strength of UV-irradiated films.

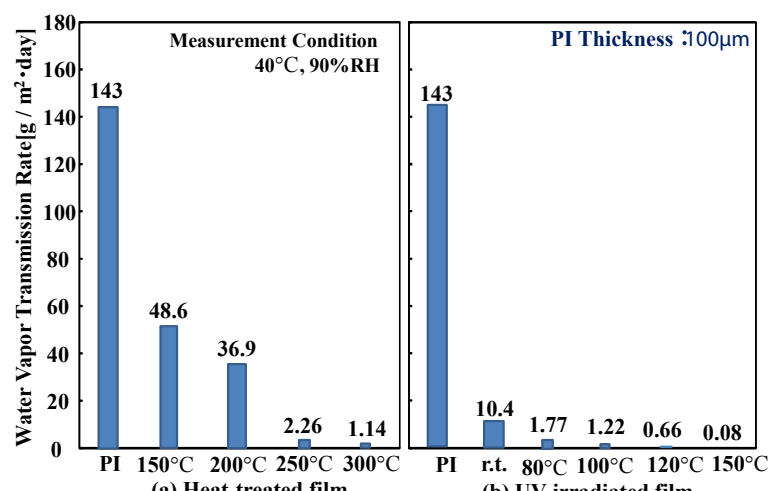

(a) Heat-treated film

(b) UV-irradiated film

Figure 5. Water Vapor Transmission Rate of polysilazane-derived $\mathrm{SiO}_{2}$ films (2-coat). 


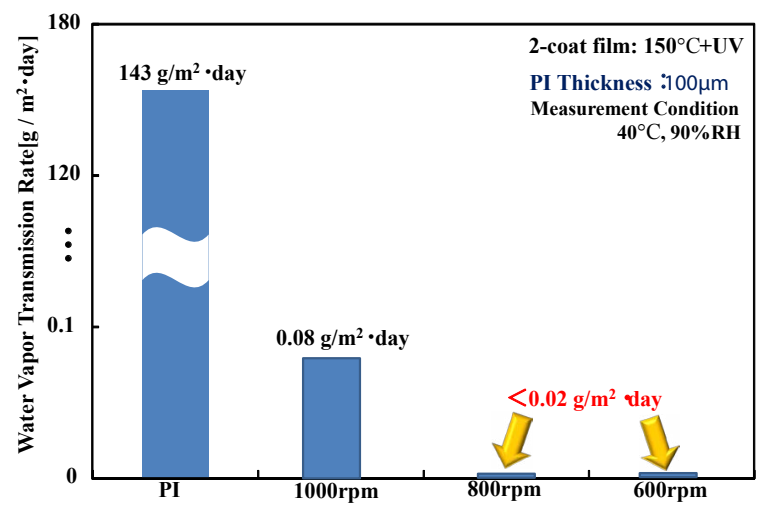

Figure 6. Film thickness dependency of WVTR for UV-irradiated films at $150^{\circ} \mathrm{C}$.

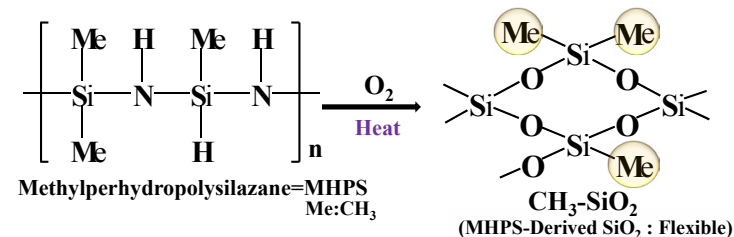

(a) Chemical structure of MHPS-Derived $\mathrm{SiO}_{2}$

\begin{tabular}{|c|c|}
\hline PHPS-Derived $\mathrm{SiO}_{2}$ & Gas barrier layer \\
Stress relaxation layer \\
\cline { 1 - 1 } MHPS-Derived $\mathrm{SiO}_{2}$ & Gas barrier layer \\
\hline PHPS-Derived $\mathrm{Si}_{2}$ & \\
\cline { 1 - 2 } PI film & \\
\cline { 1 - 2 } (b) Schematic drawing of multilayered gas barrier film
\end{tabular}

Figure 7. Chemical structure of MHPS-Derived $\mathrm{SiO}_{2}$ and schematic drawing of multilayered gas barrier film.

$\mathrm{g} / \mathrm{m}^{2}$ - day at $1000 \mathrm{rpm}$ to below $0.02 \mathrm{~g} / \mathrm{m}^{2}$ - day, which is lower than the measurement limit of the Mocon Permatran apparatus used to perform these measurements. It is thought that a lower rotation speed leads to an increase in the film thickness, and thus has a large effect on the gas barrier characteristics of the polysilazane coating.

\section{Preparation and properties of multi-layer coatings}

Increasing the number of gas barrier layers is highly effective at improving the gas barrier characteristics. However, when four or more layers of polysilazane coatings are simply applied one on top of the other, cracks are liable to form, resulting in inferior characteristics. This is thought to be because the addition of more layers makes the properties of the inorganic $\mathrm{SiO}_{2}$ glass more prominent, increasing the likelihood of stresses due to the difference in thermal expansion coefficients between the glass coating and the organic PI film substrate. We therefore decided to form a laminated coating with an intermediate layer of organic polysilazane (MHPS) (Figure 7b). As shown in Figure 7a, organic polysilazane (MHPS) has a chemical structure that consists of $\mathrm{CH}_{3}$ groups connected to a polysilazane backbone. When heated in air, it transforms into $\mathrm{SiO}_{2}$ with $\mathrm{CH}_{3}$ groups. Since this coating has organic $\mathrm{CH}_{3}$ groups in an $\mathrm{SiO}_{2}$ backbone, it adds flexibility to the coating. Also, since it is sandwiched between layers of polysilazane above and below, which have a similar molecular structure, this structure has good consistency between the multiple layers. Therefore, it is thought that a laminated gas barrier coating is suitable as a stressrelieving layer. Figure 8 shows optical micrograph images of the surface state of a four-layer (PHPS-SiO ${ }_{2}$ ) structure and a five-layer (PHPS$\mathrm{SiO}_{2}$ (2-layer)/MHPS-SiO 2 (1-layer)/PHPS-SiO (2-layer)) structure incorporating a stress-relieving layer (stress relaxation layer). Although cracks have formed in the surface of the four-layer structure, the stressrelieving five-layer structure has a smooth surface with no cracks.

Figure 9 shows a cross-sectional TEM image of the multi-layer coating film that consists of two coats of polysilazane formed by spin coating at $800 \mathrm{rpm}$ ( $220 \mathrm{~nm}$ thick), one coat of organic polysilazane ( $35 \mathrm{~nm}$ thick), and a further two coats of polysilazane ( $240 \mathrm{~nm}$ thick). In the two coats of polysilazane at the top and bottom of this structure, any interface between the polysilazane layers ( $\mathrm{PHPS}$ derived $\mathrm{SiO}_{2}$ ) were not observed, and the polysilazane layers have a uniform appearance. There are also uniform interfaces between the polysilazane (PHPS derived $\mathrm{SiO}_{2}$ )/organic polysilazane (MHPS derived $\mathrm{SiO}_{2}$ ) layers and the polysilazane (PHPS derived $\mathrm{SiO}_{2}$ )/PI film layers. No cracks formed in the multi-layer coating due to the formation of organic polysilazane as an intermediate stress-relieving layer, and tape pealing tests showed that the coating was strongly bonded with an adhesion strength of 100/100 (remaining number of sheets/ number of cuts).

Figure 10 shows the results of elemental analysis in the depth direction by XPS. Four elements: silicon $(\mathrm{Si})$, oxygen $(\mathrm{O})$, nitrogen $(\mathrm{N})$, and carbon $(\mathrm{C})$ were measured. The small amount of $\mathrm{C}$ present on the sample surface is thought to originate from surface contamination with organic material. The presence of $\mathrm{Si}, \mathrm{O}, \mathrm{C}$ and $\mathrm{N}$ in the multi-layer coating (except at the vicinity of the polyimide interface) was observed. During sputtering times of approximately 3-56 minutes and 64-116 minutes, the abundance ratio of $\mathrm{Si}$ is approximately 32 at\% and the abundance ratio of $\mathrm{O}$ is approximately 67 at $\%$. These $\mathrm{Si}$ and $\mathrm{O}$ atoms are thought to originate from $\mathrm{SiO}_{2}$ formed by the polysilazane (PHPS). The composition of the $\mathrm{SiO}_{2}$ originating from the polysilazane in the layers above and below the middle layer is very similar. The Si:O composition ratio is thought to be roughly $1: 2$. In this region, any $\mathrm{N}$ or $\mathrm{C}$ were

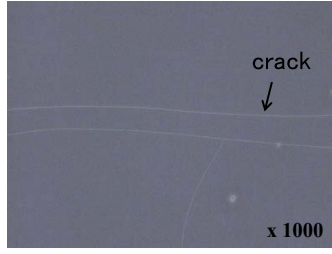

(a) $\mathrm{PHPS}_{-} \mathrm{SiO}_{2}$ (4-layer)

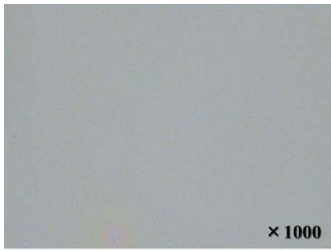

(b) $\mathrm{PHPS}_{(2 \mathrm{SiO}} / \mathrm{MHPS}_{2} \mathrm{SiO}_{2} / \mathrm{PHPS} \mathrm{SiO}_{2}$ (2-layer) (1-layer) (2-layer)
Figure 8. Optical microscope photographs of surface of the multilayered gas barrier films.

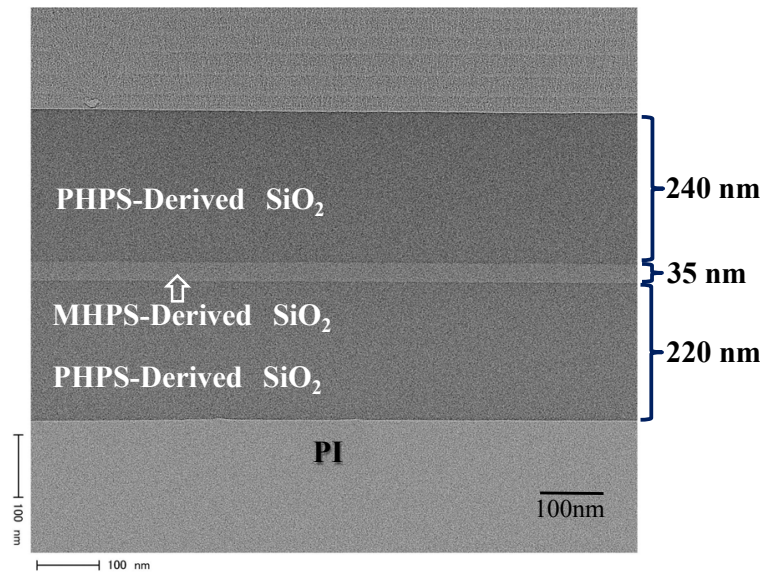

Figure 9. Cross sectional TEM photograph of the multilayered gas barrier films. 


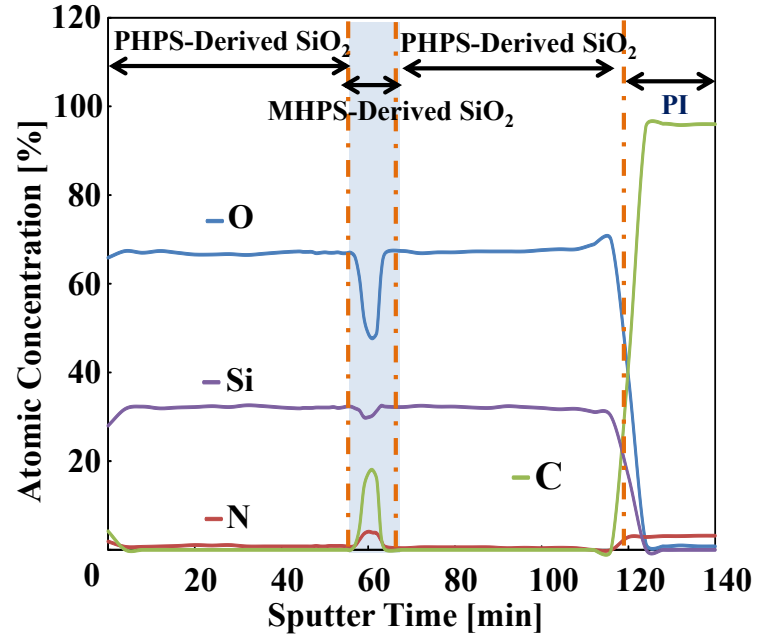

Figure 10. XPS depth profiles of elemental analysis of multilayered gas barrier films.

hardly observed. Next, in the intermediate layer over the sputtering range from 56-64 minutes, the abundance of $\mathrm{Si}$ is slightly reduced and the abundance of $\mathrm{O}$ is greatly reduced. At roughly 60 minutes, the composition was approximately 30 at $\% \mathrm{Si}$ and 49 at $\% \mathrm{O}$. On the other hand, the abundance of $\mathrm{C}$ and $\mathrm{N}$ increased in this range, reaching approximately 17 at\% $\mathrm{C}$ and 4 at $\% \mathrm{~N}$ at around 60 minutes. The $\mathrm{C}$ in this range is thought to originate from the $\mathrm{CH}_{3}$ groups of organic polysilazane (MHPS). $\mathrm{N}$ was also found to be present, but is thought to have originated from unreacted sites in the organic polysilazane. It is presumed that chemical species such as $\mathrm{Si}-\mathrm{CH}_{3}, \mathrm{SiO}_{x}(x<2)$ and $\mathrm{SiON}$ are present in this intermediate layer. When processing the organic polysilazane coating, only heat treatment at $120^{\circ} \mathrm{C}$ was performed so as to avoid decomposition of $\mathrm{Si}-\mathrm{CH}_{3}$ by light energy. It is thought that this low-temperature processing resulted in some of the unreacted organic polysilazane being left behind.

The temperature dependence of water vapor permeability in this multi-layer coating was measured. Figure 11 shows the results of plotting the natural logarithm of water vapor permeability (measured at $90 \% \mathrm{RH})$ against the reciprocal of the temperature $(1 / \mathrm{T})$ for temperatures of $40^{\circ} \mathrm{C}, 50^{\circ} \mathrm{C}$ and $55^{\circ} \mathrm{C}$. The three measured points $\left(40^{\circ} \mathrm{C}: 0.013 \mathrm{~g} / \mathrm{m}^{2}\right.$ - day, $45^{\circ} \mathrm{C}: 0.73 \mathrm{~g} / \mathrm{m}^{2}$ - day, $50^{\circ} \mathrm{C}: 2.15 \mathrm{~g} / \mathrm{m}^{2}$ day) have a linear relationship. The activation energy of water vapor transmission (obtained from the slope of the straight line by using the Arrhenius equation) is $436 \mathrm{~kJ} / \mathrm{mol}$. The water vapor permeability at room temperature $\left(25^{\circ} \mathrm{C}\right)$, which is calculated from the extrapolated straight line, is the very low value of $3.18 \times 10^{-6} \mathrm{~g} / \mathrm{m}^{2} \cdot$ day. The same linear dependence of water vapor permeability was also observed in gas barrier films formed on PET film [26]. In this case, the roomtemperature water vapor permeability and activation energy were $4.50 \times 10^{-4} \mathrm{~g} / \mathrm{m}^{2}$ - day and $219 \mathrm{~kJ} / \mathrm{mol}$, respectively. Compared with this value, the multi-layer gas barrier film proposed in this study has superior gas barrier characteristics.

The formation of an intermediate layer in order to relieve stress in a multi-layer polysilazane coating has already been reported in connection with the use of organic polymers such as polyvinyl alcohol (PVA) [27-28], but was considered to be problematic when interfacing between inorganic and organic materials or the like. The organic polysilazane (MHPS) in this study has a molecular structure that is similar to polysilazane (PHPS) and is able to bond with the polysilazane-

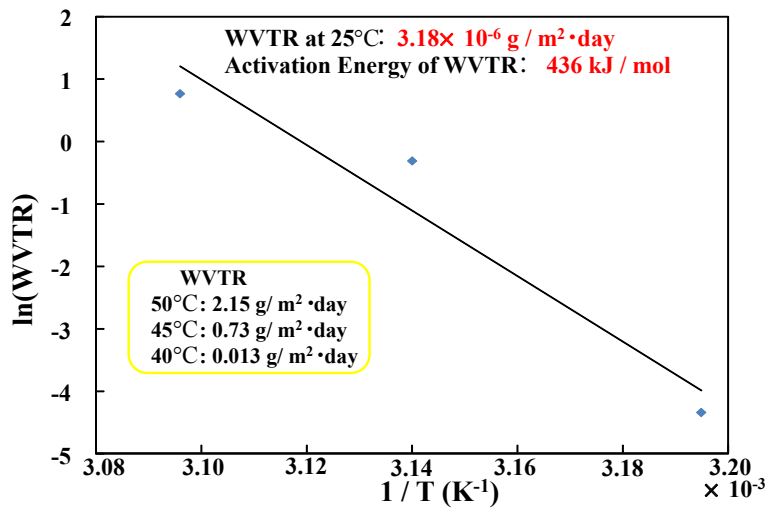

Figure 11. Temperature dependency of WVTR of the multilayered gas barrier films.

derived $\mathrm{SiO}_{2}$ layers above and below the intermediate layer. It thus has a strong adhesion force and is believed to lead to improved reliability of the gas barrier film. The multi-layer film is transparent, and the heat resistance of the alicyclic polyimide film $\left(\mathrm{Tg}: 300^{\circ} \mathrm{C}\right)$ is also high. It is therefore likely to be useful as a flexible substrate for devices such as flexible displays.

\section{Conclusion}

With the aim of developing high-performance gas barrier films, the multi-layer coating method that uses ultraviolet irradiation to a polysilazane coating formed on an alicyclic polyimide film has been investigated. By using organic polysilazane to form an intermediate stress relaxation layer, the gas barrier coating consisting of five layers was prepared. This multi-layer coating is smooth and uniform, with no cracks. Films on which this multi-layer coating has been applied exhibit superior gas barrier properties. The temperature dependence of the film's water vapor permeability indicates a linear relationship, from which it is inferred that the room temperature gas permeability is just $3.18 \times 10^{-6} \mathrm{~g} / \mathrm{m}^{2}$ - day. The film is also transparent and highly heat resistant, making it useful for the formation of flexible devices.

\section{Acknowledgement}

This work was supported by JSPS KAKENHI Grant Number 26420711 .

\section{References}

1. White MS, Kaitenbrunner MG, Istrokowacki ED, Gutnichenko K, Kettlgruber G, et al (2013) Ultrathin highly flexible and stretchable PLEDs. Nature Photonics 7: 811-816.

2. Sekitani T, Someya T (2011) Human-friendly organic integrated circuit. Materials Today 14: 398-407.

3. Sekitani T1, Zschieschang U, Klauk H, Someya T (2010) Flexible organic transistors and circuits with extreme bending stability. Nat Mater 9: 1015-1022. [Crossref]

4. Nomura K, Ohta H, Kamiya T, Hirano M, Hosono H (2004) Room-temperature fabrication of transparent flexible thin-film transistors using amorphous oxide semiconductors. Nature 432: 488-492.

5. Edited by Wong WS, Salleo A (2009) Flexible Electronics: Materials and Applications, Springer, New York.

6. Sekitani T, Someya T (2010) Stretchable, large-area organic electronics. Adv Mater 22 2228-2246. [Crossref]

7. Carcia PF, Mclean RS, Groner MD, Dameron AA, George SM (2009) Gas diffusion ultrabarriers on polymer substrates using $\mathrm{Al} 2 \mathrm{O} 3$ atomic layer deposition and $\mathrm{SiN}$ plasma-enhanced chemical vapor deposition. Journal of Applied Physics 106: 023533.

8. Yagi Y, Akashi K, (2007) Passivation films on organic film substrates designed for 

irradiation

organic electroluminescence device. Journal of Vacuum Society of Japan 50: 735.

9. Hanada T, Negishi T, Shiroishi I, Shiro T, (2010) Plastic substrate with gas barrierlayer and transparent conductive oxide thin film for flexible displays. Thin Solid Films 518: 3089.

10. Hata T, Nakayama H, (2008) An organic catalytic CVD: Principle, apparatus and applications. Thin Solid Films 516: 558 .

11. Carcia PF, MacLean RS, Reilly MH, Groner MD, George SM (2006) Catalyst of Al2O3 gas diffusion barriers grown by atomic layer deposition on polymer. Applied Physics Letters 89: 031915

12. Dameron AA, Davidson SD, Burton BB, Carcia PF, MacLean RS, et al. (2008) Gas diffusion barriers on polymer using multi layers fabricated by $\mathrm{Al} 2 \mathrm{O} 3$ and rapid $\mathrm{SiO} 2$ atomic layer deposition. Journal of Physical Chemistry C 112: 4573-4580.

13. Brinker CJ, Schere GW (1990) Sol-Gel Science. Academic Press, Boston.

14. Seyferth D, Wiseman GH (1984) High-yield synthesis of Si3N4/SiC ceramic materials by pyrolysis of a novel polyorganosilazane. Journal of American Ceramic Society 37: 132.

15. Kamiya K, Oka AI, Nasu H, Hashimoto T (2000) Comparative study of structure of silica gels from different sources. Journal of Sol-Gel Science \& Technology 495-499.

16. Iwamoto Y, Sato K, KatoT, InadaT, Kubo Y (2005) A hydrogen-perselective amorphous silica membrane derived from polysilazane. Journal of European Ceramic Society 25: 257.

17. Funayama O, TshiroY, Kamo A, Okumura M, Isoda T (1994) Conversion mechanism of perhydropolysilazane into silicon nitride-base ceramics. Journal of Material Science 29: $883-4888$

18. Ohishi T (2003) Gas barrier characteristics of a polysilazane film formed on an ITOcoated PET substrate, J Non-Cryst Solids 330: 248

19. Naganuma Y, Tanaka S, Kato C, ShindoT (2004) Formation of silica coating from perhydropolysilazane using vacuum ultraviolet excimer lamp. J Cera Soc Japan 112: 599.

20. Prager L, Dierdorf A, Liebe H, Naumov S, Stojanoviä $\ddagger$ S, et al. (2007) Conversion of perhydropolysilazane into a SiOx network triggered by vacuum ultraviolet irradiation access to flexible, transparent barrier coatings. Chemistry 13: 8522-8529. [Crossref]

21. Prager L1, Dierdorf A, Liebe H, Naumov S, StojanoviÄ $\$$ S, et al. (2007) Conversion of perhydropolysilazane into a SiOx network triggered by vacuum ultraviolet irradiation: access to flexible, transparent barrier coatings. Chemistry 13: 8522-8529. [Crossref]

22. Kobayashi Y, Yokota H, FuchitaY, Takahashi A, Sugawara Y (2013) Characterization of gas barrier silica coating prepared from perhydropolysilazane films by vacuum ultraviolet irradiation. J Ceram Soc Japan 121: 215

23. Morlier A, Cros S, Garandet J-P, Alberola N, (2012) Thin gas-barrier silica layers from perhydropolisilazane obtained through low temperature curing: A comparative study. Thin Solid Films 524: 62-66.

24. Naganuma Y, Horiuchi T, Kato C, Tanaka S (2013) Low-temperature synthesis of silica coating on a poly(ethylene terephthalate) film from perhydropolysilazane using vacuum ultraviolet light irradiation. Surface \& Coatings Technology 225: 40-46.

25. [Morlier A, Cros S, Garandet J-P, Alberola N (2014) Structural properties of ultraviolet cured polysilazane gas barrier layers on polymer substrates. Thin Solid Films 550: 8589.

26. Ohishi T, Sone S, Yanagida K (2014) Preparation and gas barrier characteristics of polysilazane-derived silica thin films using ultraviolet irradiation. Materials Sciences and Applications 5: 105-111

27. Ohishi T, Yamazaki Y, Nabatame T (2016) Preparation, structure and gas barrier characteristics of polysilazane-derived silica thin films formed on PET by simultaneously applying ultraviolet-irradiation and heat-treatment. Frontiers in Nanoscience and Nanotechnology 2:149-154.

28. Morlier A, Cros S, Garandet J-P, Alberola N (2013) Gas barrier properties of solution processed composite multilayer structures for organic solar cells encapsulation 115: 93-99.

29. Blankenburg L, Schrodner M (2015) Perhydropolysilazane derived silica for flexible transparent barrier foils using a reel-to-reel wet coating technique: Single- and multilayer structures. Surface \& Coatings Technology 275: 193-206.

Copyright: (C2016 Ohishi T. This is an open-access article distributed under the terms of the Creative Commons Attribution License, which permits unrestricted use, distribution, and reproduction in any medium, provided the original author and source are credited. 